\title{
ECONOMIC EVALUATION OF MULTIFUNCTIONAL AGRICULTURE OUTPUTS IN THE CZECH REPUBLIC: MATCHING AGRICULTURAL POLICY WITH SOCIAL REQUIREMENTS
}

\author{
Simona MIŠKOLCI \\ Department of regional and business economics, FRRMS MZLU in Brno, Brno, Czech Republic
}

This paper addresses the issue of matching agricultural policy with public preferences and willingness to pay for the possible non-market benefits that agriculture may deliver. The main goal is to review and to assess the policy relevance of the information derived by the preference-based valuation studies of non-commodity outputs of agriculture in the Czech Republic. First, the AHP was employed to examine the trade-offs between different identified functions (outputs) of agriculture, and to derive preference order in non-monetary context. In the second stage, the complex monetary value of non-market benefits was estimated using open-ended CVM question and the estimated value was then decomposed according to attribute preference weights.

Keywords: multifunctional agriculture, agricultural policy

\section{Introduction}

Historically, concept of sustainable development of multifunctional agriculture emerged in the context of the continuing crisis of conventional agriculture expressed in growing health risks, environmental loss, overproduction of low-quality products, decline in the number of producers and farm workers, etc. In contrast with the agro-industrial and post-productivity paradigms, which assume the atomistic nature of farms (and of the land associated with them), sustainable rural development suggests the potential symbiotic interconnectedness between farms and the local economy, and implies a reconfiguration of the asymmetrical relationship between society and nature, technology and expertise (Marsden and Murdoch, 2006). This vision of agriculture is fundamentally different from the one presented by the agroindustrial model. Whilst the productivist vision of rural development rests on the ongoing specialization and segregation of agriculture from other rural activities and the wider society (van der Ploeg et al., 2000), the sustainable rural development model re-integrates agriculture into local ecology and into both urban and rural society through a wide variety of multidimensional and integrated activities. According to Van der Ploeg et al. (2002), sustainable rural development is a multi-faceted process that unfolds into a wide array of different and sometimes interconnected practices (organic farming, production of high quality and region-specific products, direct marketing, landscape management, conservation of new nature values and agritourism). An important conceptual question is how, and under what social conditions, these practices can become linked together across both rural and urban spaces of production and consumption. Sevilla Guzmàn (in Marsden, 2006) argues that sustainable societies can only be constructed on the basis of sustainable, locally relevant agriculture. This vision represents rejection of the homogenizing tendencies of the neo-liberal, global modernization project and the re-direction of co-evolution towards more sustainable ways of living, that are based upon the endogenous potential of an infinite diversity of locally relevant agro-ecosystems. On this basis, Marsden (2003) defines sustainable rural development as territorially-based development that redefines nature by re-emphasizing food production and agro-ecology and that re-asserts the socio-environmental role of agriculture as a major agent in sustaining rural economies and cultures. The sustainable rural development paradigm attempts to reintegrate agriculture as a multifunctional set of practices that have the potential to enhance the interrelationships between farms and people, both within rural areas and between rural and urban areas. Thus, sustainable rural development tends to be seen as socially and politically constructed (Marsden and Sonnino, 2005) and, at the same time, as an ongoing and evolving process that requires constant reappraisal.

As a part of the development of agro-environmental policy, policymakers and researchers have attempted to evaluate the public benefits of reform using an array of methods to measure the value of non-market outputs from agriculture also in the Czech Republic (Křùmalová, 2000; Kubícková, 2004). While environmental economic techniques have been used to reveal the values attached to specific public goods, it was recognized that further research should be attempted to gain insights into the nature of trade-offs that are inherent in public preferences over the range of non-commodity outcomes. Hall et al. (2004) reviewed published evidence on how agrienvironmental reforms might be matched to measured public preferences and concluded, that the totality of existing studies provides only a partial evidence base for informing about the trade-offs that might be relevant in policy design. The question of whether value estimate (hypothetical WTP) is a valid measure of preferences is very important for policy decision makers.

Drawing on the lessons learnt from the empirical work, the objective of this paper is (1) to determine the values placed by society on the competing outputs of multifunctional agricultural production and the trade-offs people make between them; and (2) to discuss potential and limits of non-market evaluation. This is because the information and data required to develop optimal policy strategies are unique and specific for each country or region. Emphasis is put on the evaluation of non-market outputs that encompass both environmental and social benefits. The economic valuation technique used relies on a combined implementation of the Analytical Hierarchy Process (AHP) and the Contingent Valuation (CV). First, the AHP was employed to examine the trade-offs between different identified functions of agriculture and their outputs in a non-monetary context. In the second stage, the complex monetary value of non-market benefits was estimated using openended CVM question and estimated value was then decomposed according 
to attribute preference weights. The aggregate monetary value for the nonmarket benefits provided by agricultural production and partial values for each of the attributes are presented.

\section{Participative tools in policy evaluation: Stated preference evaluation of non-commodity outputs}

Evaluation in the policy context aims at rationalizing policy-making process by systematically structuring all relevant aspects of policy choices (the assessment of impacts of alternative possibilities). It is considered as a continuous activity that permanently takes place during policy-making process and different kinds of evaluation can be distinguished in a policy analysis.

Stated preference valuation methods, and most frequently it is the Contingent Valuation method (CV), ideally require survey respondents to make informed value judgments on the non-market goods under investigation. This requires information on these goods to be presented to respondents in a meaningful and understandable format, which in turn will enable them to express their preferences consistently and rationally. However the public's preferences for non-market outputs of agriculture are not well formed and very few people have an idea of what the values of relevant tradeoffs between non-market outputs are.

With respect to policy evaluation, Contingent valuation studies can provide useful insights for designers and users of surveys eliciting the public's comprehensive budgetary preferences. The logic of Contingent Valuation (CV) studies is that of inferring the distribution of economic benefits in a target population from statements of WTP elicited from a random sample of respondents (for more information about CV, see Hanley, Shogren and White 1997). (V surveys can achieve reliable results only under the condition that individuals possess a set of coherent preferences for goods, including non-commodity outputs such as landscape creation, ecological services etc. (Kahneman, 1986). However, from previous empirical research it is evident that people tend not to have previously well-defined values about noncommodity outputs (Mitchell and Carson, 1989). Consequently, respondents must construct their responses at the short time they are asked an elicitation question. Schkade and Payne (1993) point out that if responses to CV questions are indeed constructed, it could be expected to be highly sensitive to features of the task and context that would influence the process of construction. Preference-formation does not seem to take place exogenously to the survey but it is endogenous to it (Hanemann, 1994). Experimental results confirm this expectation. The order, in which questions are asked, for example, appears to influence the amounts respondents bid (Samples and Hollyer, 1990), as does the information the survey provides. Various studies (Kahneman and Knetsch, 1992; Desvousges, 1993) demonstrate the 'embedding' effect, a tendency to state the same WTP for a part of a resource as for the whole. Considering that separate valuation of each output of multifunctional agriculture through an individual CV study (due to series of "instrumental biases") could lead to seriously biased estimations, the AHP as a complementary technique to CV was suggested (see also Kallas et al., 2007; Hall et al., 2004). It is based on the assumption, that individuals'/society utility functions are additive. The sum of partial utilities $U(F)$ for each attribute is equal to the total utility of the complex good U(MF):

$$
U(M F)=U\left(F_{1}, F_{2}, \ldots, F_{n}\right)
$$

where:

- $F_{i}$ represents agricultural function $i$. Assuming following linear utility function specification, AHP allows us to estimate $w_{i}$ for each agricultural function/output $i$ :

$$
U(M F)=w_{1} F_{1}+w_{2} F_{2}+\ldots+w_{n} F_{n}
$$

hence the WTP for an individual function/output of multifunctionality is as follows:

$$
W T P_{F i}=w_{i} W T P_{M F}
$$

Assuming an additive utility function, multiplying attribute weights by the corresponding aggregated WTP provides estimates of the WTP for various levels of the attributes.

However, some individual may treat certain non-commodity outputs of agriculture differently from the manner suggested by this theoretical framework, as it was discussed above. In fact, individuals may express a zero WTP as a protest against the implication that such things as environmental services or food safety could be traded for other goods or money. No increase in marketed good can compensate this individual for a reduction in noncommodity output (WTA is infinite), but holding non-commodity constant and increasing marketed goods gives greater utility. In such cases, the noncommodity output has priority over other goods. This non-compensatory position can be viewed as an evidence of lexicographic preference. It means that utility functions including such non-commodity outputs are indefinable for an individual (axiom of continuity is violated), and indifference surfaces are single points (WTP $=0$ while WTA is infinite). In addition (Stevens et al., 1991) discussed the idea of a minimum level of market goods (measured by income) which must exist before an individual will value certain non-market goods. This amount of consumption could be regarded as a lowest level of marketed goods that ensured human survival or a minimum standard of living. Welfare economics apply Kaldor-Hicks compensation test, which allows for projects to be approved, where there is potential, that gainers can compensate losers and still be better off than before the policy action. This criterion becomes inoperable once compensatory amounts become infinite. Furthermore, CBA that aims to account for the positive and negative welfare consequences of a policy/project by converting them to single metrics - monetary flows, is meaningless under non-compensatory preferences.

Second theoretical problem for $\mathrm{CV}$ research to be discussed here is the pervasive influence of citizen preferences. The problem arises in establishing the relevance of WTP, insofar as it measures individual welfare, to citizen preferences, which by definition concern goods or goals other than individual welfare. They also reflect values individuals typically pursue through civic and political associations, not through actual or hypothetical market transactions.

Hence, two relevant research questions in the context of preferencebased valuation of non-commodity outputs of agriculture in the (zech Republic are (1) whether any individual seems to actually hold lexicographic preferences and (2) what is the main motive of their willingness to pay

The AHP method that was employed to examine the trade-offs between different identified functions of agriculture and their outputs in nonmonetary context, was originally created by Saaty (1980) as a structured, but flexible technique for making decisions in a multicriteria context. The method is based on approaching complex decisions using a hierarchical structure. It allows setting up a range of preference choice sets without including a price attribute. Respondents make pair wise comparisons between identified agricultural functions/outputs (targets of policy support). From these observed choices, preference weights wi and preference order can be derived. The AHP does not directly include a valuation of respondent preferences, which has been estimated using open-ended contingent valuation question. However, it allows to develop a set of coherent preferences for non-commodity outputs and to make better informed value judgments on the non-market goods under investigation. 


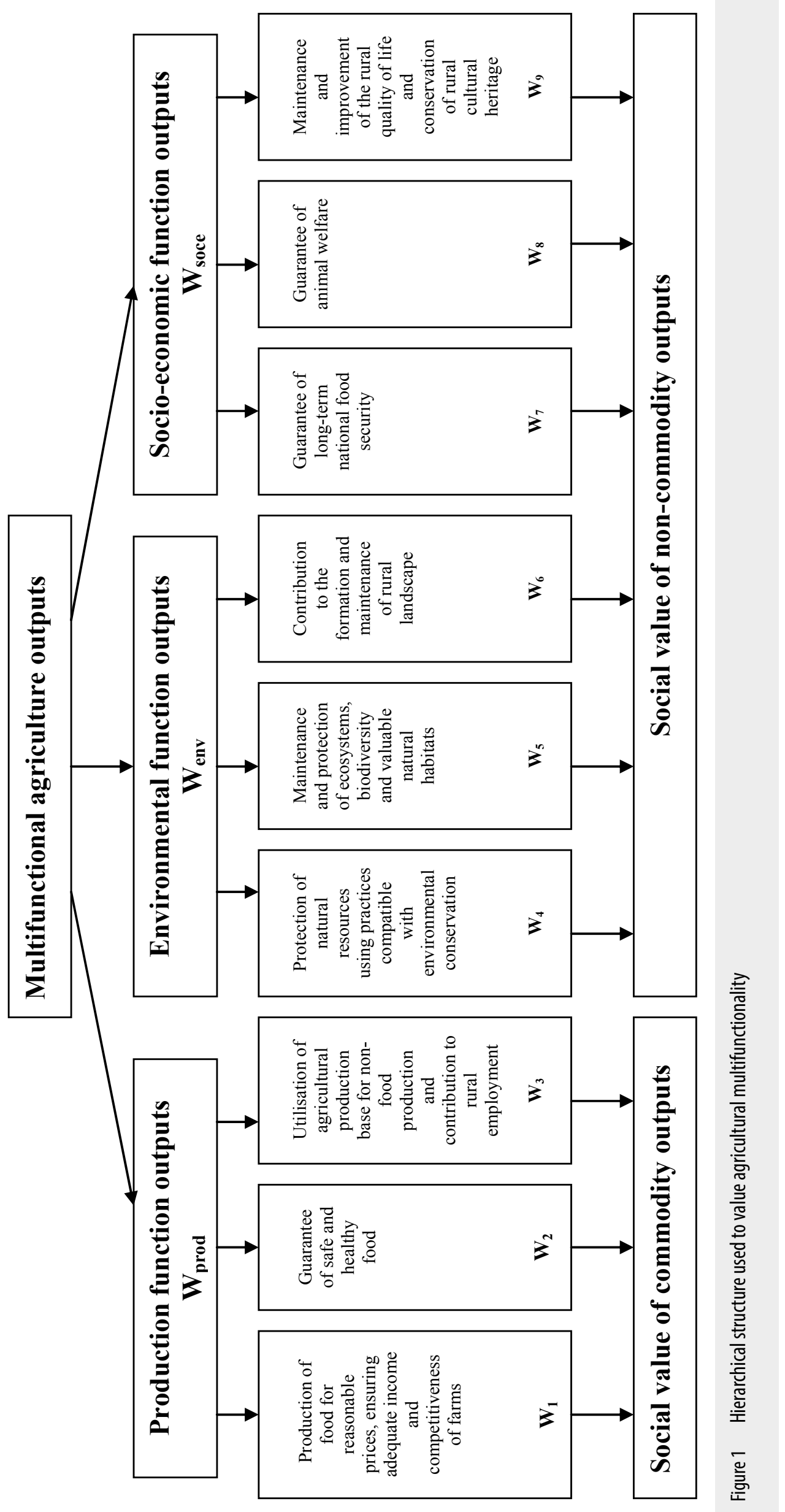


The agricultural policy-decision problem can be understood by examining a hierarchical structure of agricultural functions and its possible outputs (policy goals). In our case, according to the information gained from the literature review, the hierarchical structure was designed and explained in three levels: the complex agricultural outcome at the highest level of the structure, functions of agriculture (type of outputs) at an intermediate level, and main outputs of different functions forming the base of the structure. Figure 1 shows this three-level structure.

Within this hierarchical structure, the relative importance or weighting of each criterion or sub-criterion $\left(w_{i}\right)$ is obtained from paired comparisons of criteria. Such paired comparisons are rather easier to understand and answer by respondents than the simultaneous comparison of all objectives within the same structural level. In order to utilize these comparisons, Saaty (1980) proposed and justified the use of a 1-9 scale, as shown in Table 1. As in most empirical studies using AHP, we used this linear scale in our research, since it is intuitive and easy to deal with by previously untrained respondents.

Table 1 The AHP pair wise comparison scale

\begin{tabular}{|l|l|}
\hline Degree of importance $(w)$ & \multicolumn{1}{c}{ Definition } \\
\hline 1 & - both outputs are equally important \\
\hline 3 & - very slight importance of one output over the other \\
\hline 5 & - moderate importance of one output over the other \\
\hline 7 & - demonstrated importance of one output over the other \\
\hline 9 & - extreme or absolute importance of one output over the other \\
\hline
\end{tabular}

Thus, in order to determine the weightings assigned to each of the proposed multifunctionality attributes, respondents (representing society as a whole) must make two kinds of comparisons; first, pair comparisons between the functions of multifunctional agriculture (three sets of pair comparisons in the present case), and secondly, pair comparisons between specific outputs of each function. Each respondent thus generates three Saaty's matrices $A$, where $a_{i j}$ represents the score obtained from comparing sub-criterion $i$ and sub-criterion $j$ :

$$
A=\left[\begin{array}{cccc}
a_{11} & a_{12} & \ldots & a_{1 n} \\
a_{21} & a_{22} & \ldots & a_{2 n} \\
\ldots & \ldots & a_{i j} & \ldots \\
a_{n 1} & a_{n 2} & \ldots & a_{n n}
\end{array}\right]
$$

This square matrix possesses two key properties:

a) its principal diagonal is filled by 1 's $\left(a_{i i}=1\right.$ for any $\left.i\right)$,

b) it verifies reciprocity among pair comparisons (if $a_{i j}=x$ then $a_{j i}=1 / x$ ).

If the respondent is perfectly consistent, scores given to pair comparisons actually represent rations among weightings allocated to the corresponding sub-criteria by a perfectly rational decision-maker:

$$
a_{i j}=w_{i} / w_{j}
$$

for any $i$ and $j$

The hierarchical structure of the AHP implies that the specific weightings $\left(w_{i}\right)$ obtained for each level should always add up to one (i.e.: $w_{\text {prod }}+w_{\text {env }}$ $+w_{\text {soce }}=1, w_{1}+w_{2}+w_{3}=1$, etc.). Therefore, if we subsequently wish to compare the relative importance allocated to the different specific outcomes (objectives) proposed, it is necessary to obtain the corresponding normalized weights $\left(w_{i}^{\prime}\right)$ as shown in Figure 2. These normalized weights are obtained by multiplying each of the weight of sub-criterion by the weight of the criterion immediately above it in the hierarchical structure, i.e., $w_{1}{ }^{\prime}=w_{\text {prod }} \times w_{1}$, etc. Thus, normalized weights for all of the specific objectives once again add up to one, and each $w^{\prime}$ ' becomes an indicator of the importance of output $i$ across the whole set of specific agricultural function outputs considered.

Initially, the AHP decision technique was designed for individual decision-makers, but was promptly extended for group decisions (Easley et al., 2000). For these purposes, Saaty (1991) propose the geometric average method to aggregate the pair comparisons of the Saaty's matrices $\left(A_{k}=\right.$ $a_{i j}$ ) from the m people who make up the group (sub-index k) to obtain the aggregated Saaty's matrix:

$$
A=a_{i j}=\sqrt[m]{\prod_{k=1}^{k=m} a_{i j k}}
$$

Finally, the vector of weights for the different criteria derives from this aggregated matrix. Along the same lines, Gass and Rapcsàk (1998) propose as an alternative using the arithmetic average or the geometric average to aggregate the $w_{i k}$ weights from each person $k$ :

$$
w_{i}=\frac{\sum_{k=1}^{k=m} w_{i k}}{m} \quad \text { or } \quad w_{i}=\sqrt[m]{\prod_{k=1}^{k=m} w_{i k}}
$$

in order to estimate the representative weightings for the whole group. The second option referred to as aggregation of individual preferences (AIP), was adopted in reported studies. According to the Forman and Peniwati (1998), the AIP method estimated by the geometric average is more appropriate for group decisions in the social field.

\section{Material and methods}

The reported studies were conducted in the Region NUTS II South-east (the Czech Republic). Although limited transferability of study results was emphasized, it is worth taking into account the importance of agriculture for this Region. Agricultural land covers $60 \%$ of the total area of $13,919 \mathrm{~km}^{2}$ of this Region. Total population is 1,647,929 inhabitants and HDP per person is approx. $11,000 €(72 \%$ of EU27 average and $92 \%$ of CZ average). Agriculture generates from $5.1 \%$ (in the Region NUTS III South Moravia) to $12.6 \%$ (in the Region NUTS III Vysocina) of Region's employment, both values being higher than national average (4.8\%). Although from the private point of view, farming is at the margin of economic performance in some areas, it still has an important role from the social point of view in terms of the ratio of actively farmed land in LFA with the highly valued agricultural landscape ( $45.1 \%$ of Region's total agricultural land).

The principal challenges in the CV study design were to identify what aspects of the complex agricultural output needed to be communicated to the general public, thus forming the focus of the valuation exercise, and to design effective ways of conveying the information. The feedback from pilot surveys on focus groups using verbal descriptions of the multiple functions of agriculture and their outputs indicated that the large volume of new information about the bundle of agricultural outputs requiring presentation led both to confusion and respondent fatigue. The adoption of a more visual and interactive approach was therefore considered more suitable. We used verbal description supported with a written Information Pack with pictures visualizing hierarchical structure of agricultural outputs (Figure 1). Following the presentation of this information, respondents were provided with an opportunity to discuss and clarify with the interviewer any issues of outstanding confusion. The pair-wise comparisons were framed in the form of 
question: how important is agricultural output i relative to agricultural output $j$. Cognitive burden was thus reduced as the comparisons of importance were always between two functions or outputs instead of evaluation of a large bundle of outputs. Moreover, as it is assumed that respondent is consistent in judgments about any one pair criteria, following use of the reciprocal allows only $n(n-1) / 2$ comparisons to be made where there are $n$ criteria.

The problem with CV application is also how to deal with negative WTP. This problem has been discussed in a series of articles. It is widely accepted that WTP on theoretical backgrounds can be negative. According to Kriström (1995), the correct way of CVM application is to gather information from the respondents that allows for a distinction to be made between zeros, negative and protest WTP bids. This was done by inclusion of follow-up questions in the survey instrument that ask for the respondent's motives for stating a zero bid in order to distinguish the following categories of respondents:

1. Stating WTP $>0$.

2. Stating $W T P=0$ or synonymous reply:

a) being indifferent, 'true' $W T P=0$;

b) having negative WTP, WTP $<0$;

c) defined as protest bidders.

The survey consisted of a sample of 408 valid questionnaires returned in 2008 and 180 returned in 2011 by a sample drawn from a total population in the region South-East of 1,646,929 inhabitants. Sample points were selected across this region. Again, sub-stratification was determined using a quota system based on social grade, age and gender. The questionnaire consisted of following basic elements:

$\square$ Investigation of the existence of genuine concern for the support of multifunctional agriculture and provision of non-commodity services by agriculture.

$\square$ Pair comparisons among the various agricultural functions and their outputs. This information was used to implement the AHP analysis.

$\square$ WTP evaluation questions. This information was used to implement Contingent Valuation analysis.

$\square$ Motives to state positive or 0 WTP.

$\square$ Socio-economic questions.

\section{Results and discussion}

The application of the methodology described above to the elements of the sample enables to obtain the weightings that the sample assigns to each individual agricultural output/objective of the agricultural policy. The preference ratings, and their reciprocals, were collected in four comparison matrices for each respondent and each year, specific weights $\left(w_{i}\right)$ were then estimated, which are consistent with the relativities between the agricultural functions or outputs/policy objectives contained in the matrix by calculating the geometric mean of each row and normalizing these by dividing by the sum of geometric means for each row. Then, the normalized specific weights $\left(w_{i}^{\prime}\right)$ were calculated and all results for each year (2008 and 2011) were aggregated. The final results are shown below in Figure 2.

Although these results are not fully comparable, we can still derive the main trends in preference development in relation to current situation in Czech agriculture. The sample of the citizens of the Region South-East considers the production function as the most important function of agriculture, followed by environmental function and socio-economic function.

The importance of production function is growing in recent years. Altogether, production function benefits generated approximately $44.8 \%$ of the economic value in 2008, while in 2011, the perceived importance is higher $-52.5 \%$ of the complex agricultural output value. It is highly probable that this preference shift can be explained in context of the continuing crisis of agriculture expressed in decline in the number of domestic producers and growing health risks associated with low quality of imported food and unethical retailers' behavior. From the methodological point of view, it could be considered as an evidence of CV methodology to capture changes in preferences. This logic can be supported also by changes in normalized specific weights for related agricultural functions (summarized in Table 2). The most important are:

$\square$ Production of food for reasonable prices, ensuring adequate income and competitiveness (increase from $w_{1}^{\prime}(2008)=0.1236$ to $\left.w_{1}{ }^{\prime}(2011)=0.2467\right)$.

$\square$ Guarantee of safe and healthy food (approximately the same high importance $w_{2}^{\prime}(2008)=0.2046$ and $\left.w_{2}^{\prime}(2011)=0.1913\right)$.

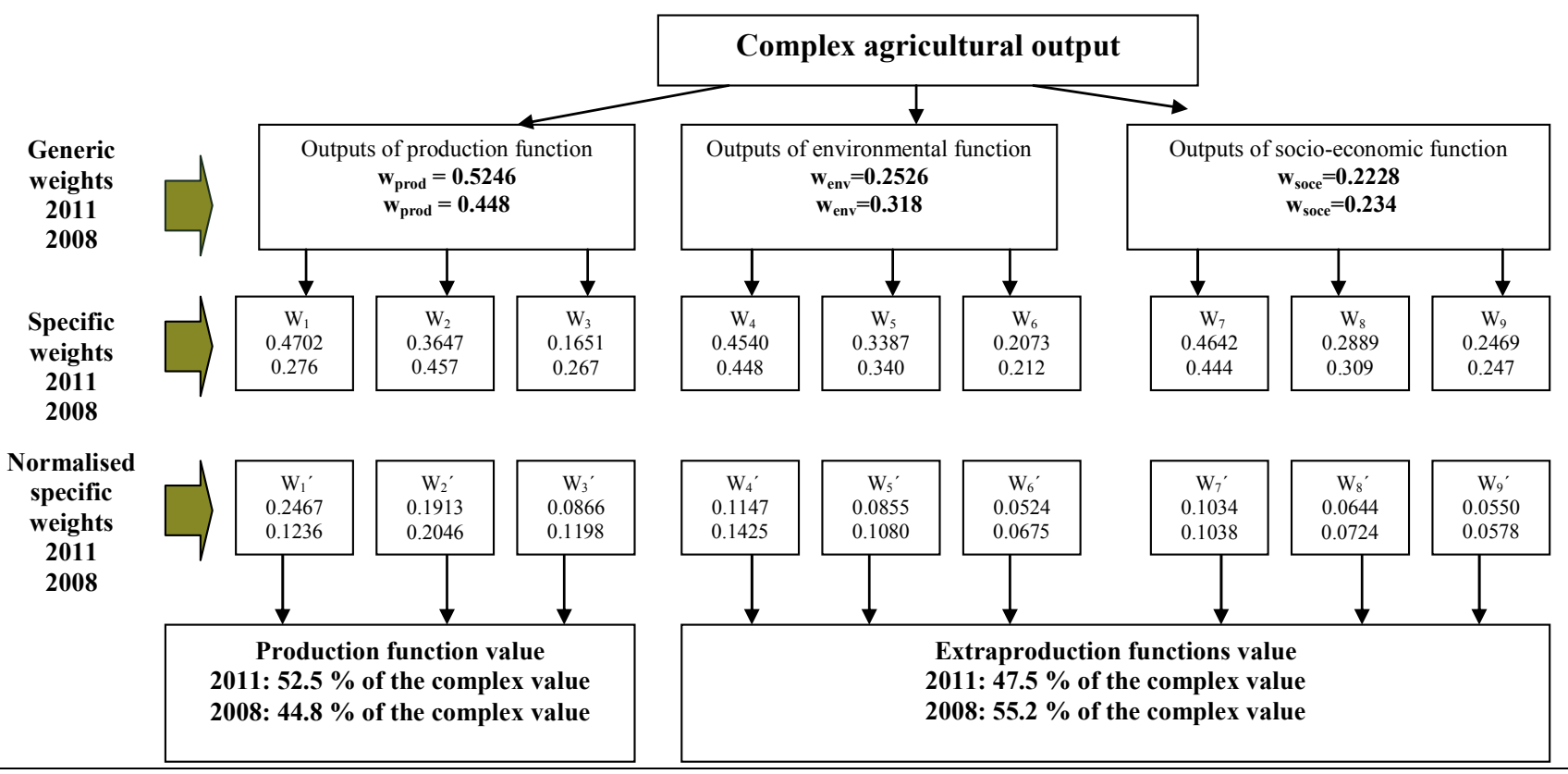

Figure 2 Results of agricultural function outputs weighting: 2011 and 2008 results comparison 
Table 2 The preference order of identified agricultural outcomes

\begin{tabular}{|c|c|c|c|c|c|}
\hline \multirow{2}{*}{$\begin{array}{l}\text { Preference } \\
\text { order }\end{array}$} & \multirow[t]{2}{*}{ Type of agricultural outcome } & \multicolumn{2}{|c|}{ Preference order } & \multicolumn{2}{|c|}{ Normalized specific weight } \\
\hline & & 2008 & 2011 & 2008 & 2011 \\
\hline \multirow{3}{*}{ 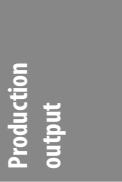 } & production of food for reasonable prices, ensuring adequate income and competitiveness of farms & 3. & 1. & 0.1236 & 0.2467 \\
\hline & guarantee of safe and healthy food & 1. & 2. & 0.2046 & 0.1913 \\
\hline & $\begin{array}{l}\text { utilization of agricultural production base for non-food production and contribution to rural employ- } \\
\text { ment }\end{array}$ & 4. & 5. & 0.1198 & 0.0866 \\
\hline \multirow{3}{*}{ 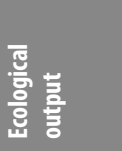 } & protection of natural resources using practices compatible with environmental conservation & 2. & 3. & 0.1425 & 0.1147 \\
\hline & maintenance and protection of ecosystems, biodiversity and valuable natural habitats & 5. & 6. & 0.1080 & 0.0855 \\
\hline & contribution to the formation and maintenance of rural landscape & 8. & 9. & 0.0675 & 0.0524 \\
\hline \multirow{2}{*}{ 흥 흥 흥 흘 } & guarantee of long-term national food security & 6. & 4. & 0.1038 & 0.1034 \\
\hline & guarantee of animal welfare & 7. & 7. & 0.0724 & 0.0644 \\
\hline
\end{tabular}

$\square$ Guarantee of long-term national food security (approximately the same high importance $w_{7}^{\prime}(2008)=0.1038$ and $\left.w_{7}^{\prime}(2011)=0.1034\right)$.

Slightly decreasing importance was assigned to utilization of agricultural production base for non-food production and contribution to rural employment (decrease from $w_{3}{ }^{\prime}(2008)=0.1198$ to $\left.w_{1}{ }^{\prime}(2011)=0.0866\right)$.

The increase of production function importance in complex agricultural output was compensated by the decrease of environmental function weight. Altogether, environmental function benefits generated approximately $31.8 \%$ of economic value in 2008, while in 2011, the perceived importance is lower $25.3 \%$ of complex agricultural output value. This could be partly explained by the increase in environmental performance of farms in the Czech Republic and relatively increasing awareness about food safety and security. The most valued environmental function was protection of natural resources using practices compatible with environmental conservation (decrease from $w_{4}$ ' $(2008)=0.1425$ to $\left.w_{4}{ }^{\prime}(2011)=0.1147\right)$, which could be also closely related to the above mentioned production functions.

Relatively the same importance has been assigned by respondents to socio-economic functions - $23.4 \%$ in 2008 and $22.3 \%$ in 2011. To guarantee long-term national food security was identified as the most preferred and valuable outcome/service of socio-economic functions delivered to society, creating almost $10.3 \%$ of the total benefit from complex agricultural outputs in both reported years.

Although the animal welfare, landscape maintenance and contribution to rural life quality and cultural heritage was valued relatively lower, estimated shares of total benefit of these non-commodity outputs derived from agriculture are considerable and stable.

In conclusion, citizens of the Region South-East of the Czech Republic are willing to support domestic agriculture, firstly as a producer and provider of the safe and high-quality food. Findings also show the relatively lower importance of environmental externalities (caused by increase of relative importance of production function) and stable importance of socio-economic externalities for our respondents.

Based on the normalized weight for identified agricultural outcomes, the preference order has been set to investigate priority of agricultural policy objectives. The relative importance of each output and thus possible trade-offs within policy options are quantified using the normalized specific weights, which also represent shares of all the identified outputs on the value of complex agricultural output. The ranking of preferences for agricultural outputs that can be used for priority setting by policy-makers is shown in Table 2.

\section{Results}

Following the priority settings, the respondents were asked an open-ended CV question whether and how much they would be willing to pay through their annual taxes to support non-commodity outputs of extra-production functions. This established three groups of respondents: those prepared to pay in principle, non-payers, and protesters. From the results summarized in Table 3 we can derive that the share of respondents who stated positive WTP was slightly increasing from $63 \%$ of the total sample of respondents in 2008 to $67 \%$ in 2011. Most of the respondents refusing to pay anything (WTP=0) were classed as "protest bidders": this gives an overall protest level $26 \%$ of the total sample. In both investigated years, the most common reasons for protesting were that the respondents did not believe that their money would be used for the stated purpose and that it is unfair to ask people for the contribution. The share of respondents stated "genuine zeros" was relatively low and stable ( $3 \%$ of the total sample) and the share of respondents stated "negative WTP" $(W T P<0)$ was growing from $3 \%$ to $8 \%$ of the total samples.

Table 3 shows the results of a descriptive statistical analysis of the openended CV data set results. The stated willingness to pay increased from mean WTP 84.90 CZK/p/month/2008 to mean WTP 193.86 CZK/p/month/2011. As usual in CVM studies, both the median and trimmed mean lie below the true mean; this is due to the influence on the latter of the values in the upper tail of the distribution. Both standard deviation WTP $114.18 \mathrm{CZK} / \mathrm{p} / \mathrm{month} / 2008$ and $259.47 \mathrm{CZK} / \mathrm{p} / \mathrm{month} / 2011$ is less than twice the mean, which is somewhat lower than is often the case in CV.

The lowest non-zero bid was 5 CZK/p/month and the highest 1,100 $\mathrm{CZK} / \mathrm{p} / \mathrm{month} / 2011$. If we have the ambition to measure a sheer value of nonmarket benefits of agriculture, it seems relevant to exclude the respondents having negative WTP and the respondents defined as protest bidders from the sample, since we do not have any information on their preferences for these agricultural services. The mean of WTP $\left(\mathrm{n}^{*}=277\right)$ is $125 \mathrm{CZK} / \mathrm{p} / \mathrm{month} / 2008$ and WTP $\left(\mathrm{n}^{*}=126\right)$ is $277 \mathrm{CZK} / \mathrm{p} / \mathrm{month} / 2011$.

Using the AHP method, the share on the total value of complex agricultural output for each defined agricultural output (i) was derived, and normalized specific weights wi' are presented above (Table 2). Normalized specific weights were calculated on an individual basis. The calculations were carried out in the same manner as before, but repeated for each respondent who stated a WTP amount or genuine zero. This allowed individual WTP amounts to be decomposed according to the overall weightings given to each 
Table 3 WTP for non-commodity outputs of agriculture - CV data analysis results

\begin{tabular}{|c|c|c|c|}
\hline \multirow[t]{2}{*}{ Variable } & \multirow[t]{2}{*}{ Unit } & \multicolumn{2}{|c|}{ Value } \\
\hline & & 2008 & 2011 \\
\hline n & Resp. & 408 & 180 \\
\hline$W T P>0$ & $\%$ & 63.24 & 67.2 \\
\hline$W T P=0$ & $\%$ & 36.76 & 32.8 \\
\hline$W T P<0$ & $\%$ & 3.19 & 8.33 \\
\hline Protest & $\%$ & 26.47 & 25.56 \\
\hline$n^{*}$ & resp. & 277 & 126 \\
\hline $\operatorname{Mean}(n)$ & CZK/p/month & 84.90 & 193.86 \\
\hline Mean $\left(n^{*}\right)$ & CZK/p/month & 125.05 & 276.94 \\
\hline Mean (WTP) & CZK/p/month & 134.26 & 288.38 \\
\hline Median $(n)$ & CZK/p/month & 50 & 100 \\
\hline Median $(W T P>0)$ & CZK/p/month & 100 & 200 \\
\hline Modus $(W T P>0)$ & CZK/p/month & 100 & 100 \\
\hline STDEV $(n)$ & CZK/p/month & 114.18 & 259.47 \\
\hline Trimmean (95 \%) & CZK/p/month & 50 & 99.34 \\
\hline Min WTP & CZK/p/month & 5 & 5 \\
\hline Max WTP & CZK/p/month & 1,000 & 1,100 \\
\hline
\end{tabular}

$n^{*}$ - shows the total of genuine zeros plus positive WTP bids

$1 €=25$ CZK (2008); 24.50CZK (2011)

Table 4 Decomposition of WTP for complex agricultural outputs

\begin{tabular}{l} 
Specific agricultural output \\
\hline $\begin{array}{l}\text { Production of food for reasonable prices, ensuring adequate income } \\
\text { and competitiveness of farms }\end{array}$ \\
\hline Guarantee of safe and healthy food \\
\hline $\begin{array}{l}\text { Utilization of agricultural production base for non-food production } \\
\text { and contribution to rural employment }\end{array}$ \\
\hline $\begin{array}{l}\text { Protection of natural resources using practices compatible with } \\
\text { environmental conservation }\end{array}$ \\
\hline $\begin{array}{l}\text { Maintenance and protection of ecosystems, biodiversity and valuable } \\
\text { natural habitats }\end{array}$ \\
\hline Contribution to the formation and maintenance of rural landscape \\
\hline Guarantee of long-term national food security \\
\hline Guarantee of animal welfare \\
\hline $\begin{array}{l}\text { Maintenance and improvement of the rural quality of life } \\
\text { and conservation of rural cultural heritage }\end{array}$
\end{tabular}

\begin{tabular}{|c|c|c|c|c|c|c|c|}
\hline \multicolumn{2}{|c|}{ Preference order } & \multicolumn{2}{|c|}{ Normalized specific weight } & \multicolumn{2}{|c|}{ Mean WTP } & \multicolumn{2}{|c|}{ Mean WTP $\left(n^{*}\right)$} \\
\hline 2008 & 2011 & 2008 & 2011 & 2008 & 2011 & 2008 & 2011 \\
\hline 3. & 1. & 0.1236 & 0.2467 & 20.94 & 47.83 & 15.46 & 68.32 \\
\hline 1. & 2. & 0.2046 & 0.1913 & 16.24 & 37.09 & 25.59 & 52.98 \\
\hline 4. & 5. & 0.1198 & 0.0866 & 7.35 & 16.79 & 14.98 & 23.98 \\
\hline 2. & 3. & 0.1425 & 0.1147 & 9.74 & 22.24 & 17.82 & 31.77 \\
\hline 5. & 6. & 0.1080 & 0.0855 & 7.26 & 16.58 & 13.51 & 23.68 \\
\hline 8. & 9. & 0.0675 & 0.0524 & 4.45 & 10.16 & 8.44 & 14.51 \\
\hline 6. & 4. & 0.1038 & 0.1034 & 8.78 & 20.05 & 12.98 & 28.64 \\
\hline 7. & 7. & 0.0724 & 0.0644 & 5.47 & 12.48 & 9.05 & 17.83 \\
\hline 9. & 8. & 0.0578 & 0.0550 & 4.67 & 10.66 & 7.23 & 15.23 \\
\hline- & - & 1 & 1 & 84.90 & 193.86 & 125.05 & 276.94 \\
\hline
\end{tabular}

$n^{*}$ - shows the total of genuine zeros plus positive WTP bids

$1 €=25$ CZK (2008); 24.50CZK (2011)

non-market output of agriculture. Individual WTP for each identified service of agriculture by the means of estimation are presented in the Table 4.

Considering the total sample of respondents, we find that on average $5 \%$ of respondents refuse to pay because of their ethical position, consistent with lexicographic preferences. Approximately $26 \%$ of total number of respondents was failing to show their true preferences under contingent valuation method (they mostly protest against payment vehicle). The abovementioned results support the applicability of preference based CV method for the evaluation of non-commodity outputs of agriculture in the Czech Republic. The rejection of a single metric might raise the evidence of plural, incommensurable nature of some non-commodity outputs of agriculture. Thus, some of non-commodity outputs of agriculture that would be regarded as a commodity in neoclassical valuation framework may be given a moral standing and ranked in hierarchical manner in comparison with other commodities.

Motives for valuing the non-commodity outputs of agriculture are presented in the last rows of Table 5. As the willingness to pay question in analyzed CV studies was presented before the follow-up questions examining motives, the framing of WTP question might have had an effect on expressed motives. Despite of that potential bias, CV results show that 
Table 5 Lexicographic and citizens preferences for non-commodity outputs of agriculture revealed in selected CV studies (share of respondents)

\begin{tabular}{|c|c|c|}
\hline \multirow{2}{*}{$\begin{array}{l}\text { Selected indicators of the structure of respondents } \\
\text { according to revealed preferences }\end{array}$} & \multicolumn{2}{|c|}{ Structure of the sample } \\
\hline & 2008 & 2011 \\
\hline Number of respondents $(\mathrm{n})$ & 408 & 180 \\
\hline Positive bid (WTP >0) & $63.25 \%$ & $67.2 \%$ \\
\hline No Bid & $36.75 \%$ & $32.8 \%$ \\
\hline No Value (true WTP=0) & $4.64 \%$ & $2.77 \%$ \\
\hline Negative value $(W T P<0)$ & $3.21 \%$ & $8.33 \%$ \\
\hline Protest WTP & $26.46 \%$ & $25.56 \%$ \\
\hline Respondents with ethical LP (from n) & $5.89 \%$ & $4.44 \%$ \\
\hline Ethical LP from respondents with no bid & $16.03 \%$ & $12.12 \%$ \\
\hline Ethical LP from all respondents with protest bid & $22.26 \%$ & $17.39 \%$ \\
\hline Respondents with positive qualitative valuation & $82 \%$ & $84 \%$ \\
\hline Instrumental value motives (WTP $>0$ ) & $40 \%$ & $49 \%$ \\
\hline Altruistic value motives (WTP > 0 ) & $81 \%$ & $78 \%$ \\
\hline
\end{tabular}

most of the respondents considered citizens preferences and altruism and bequest motives. The results support existing evidence of the importance of non-use values and environmental values in relation to non-commodity outputs of agriculture. In terms of CVM methodology, the reported results of CV studies also imply that greater attention needs to be paid to the elicitation format. The respondents with strong ethical (altruistic) motives for WTP can show non-exchange values that cannot be regarded as commensurable with market values.

\section{Conclusions}

Multifunctionality of agriculture must be sufficiently recognized, acknowledged and sensitively supported so that agriculture can fulfill its potential for impletion of social mission in sustainable development. Optimal agricultural support policy should be based among others on the identification of the public objectives that are to be achieved. As a part of the development of agro-environmental policy, policy-makers and researchers have attempted to evaluate the public demand and the value of non-market outputs from agriculture. While environmental economic techniques have been used to reveal the values attached to specific non-commodity outputs, it was recognized that further research should be attempted to gain insights into the nature of trade-offs that are inherent in public preferences over the range of non-commodity outcomes. This paper aims to analyze public preferences for agricultural outputs in terms of the relative weights that citizens assign to the various possible agricultural outcomes and to estimate the economic value of the non-market outputs.

The results show that the importance of production function is growing in recent years in the Czech Republic. Overall "Production of food for reasonable prices, ensuring adequate income and competitiveness of farms", and to "guarantee safe and healthy food" are the most preferred services of agriculture. Citizens of the Region South-East of the Czech Republic are willing to support domestic agriculture, firstly as a producer and provider of the safe and high-quality food. Findings also show the relatively lower importance of environmental externalities (caused by increase of relative importance of production function) and stable importance of socio-economic externalities for our respondents. The stated willingness to pay increased from mean WTP $84.90 \mathrm{CZK} / \mathrm{p} / \mathrm{month} / 2008$ to mean WTP $193.86 \mathrm{CZK} / \mathrm{p} / \mathrm{month} / 2011$. The complex monetary value of non-market benefits was estimated using open- ended CVM question, and estimated value was then decomposed according to normalized specific preference weights for each non-commodity output derived by AHP method. From the policy-making point of view, it is also worth to point out here that the weightings obtained from AHP for society as a whole are averages, coming from a wide range of positions in reality. In this socio-political context, the final policy-decisions will not necessary fit with the demand of majority of society, but it is also dependent on the ability of social groups (lobbies) to push through their opinions. The results also support existing evidence of the importance of non-use values and environmental values in relation to non-commodity outputs of agriculture. The reported results of CV studies also imply that greater attention needs to be paid to the elicitation format. The responses to CV questions concerning non-commodity outputs are dominated by citizen judgments concerning social goals and responsibilities rather than by consumer preferences. These methodological problems can be resolved by adopting a more deliberative, discursive and constructive approach to evaluating the non-commodity outputs of agriculture.

The paper is a partial output of a Research project of FBE MUAF Brno, (MSM No 6215648904) "(zech economy in the process of integration and globalisation, and the development of agrarian sector and the service sector under the new conditions of an integrated marked" as a part of thematic direction 05 "Socialeconomic context of sustainable development of multifunctional agriculture, and actions of agrarian and regional policy".

\section{References}

DESVOUSGES, W. H. - REED JOHNSON, F. - DUNFORD, R. W. - BOYLE, K. J. - HUDSON, S. P. - WILSON, K. N. 1993. Measuring natural resource damages with contingent valuation: tests of validity and reliability. In: Hausman, J. A. (Ed.), Contingent Valuation: A Critical Assessment. North Holland, Amsterdam, 1993. pp. 91-164.

EASLEY, R. F. - VALACICH, J. S. - VENDATARAMANAN, M. A. 2000. Capturing group preferences in a multicriteria decision. In: European Journal of Operational Research, 2000, no. 125, p. 73-83.

FORMAN, E. - PENIWATI, K. 1998. Aggregating individual judgments and priorities with the Analytic Hierarchy Process. In: European Journal for Operational Research, 1998, no. 108 , pp. $165-169$. 
GASS, S.I. - RAPCSÁK, T. 2004. Singular Value Decomposition in AHP. In: European Journal of Operational Research, 2004, no. 154, p. 573-584.

HALL, C. - MCVITTIE, A. - MORAN, D. 2004. What does the public want from agriculture and the countryside? A review of evidence and methods. In: Journal of Rural Studies, vol. 20, 2004, no. 2, p. 211-225.

HANEMANN, W. M. 1994. Valuing the environment through contingent valuation. In: Journal of Economic Perspectives, no. 8, 1994, p. 19-43.

HANLEY, N. - SHOGREN, J. F. - WHITE, B. 1997. Environmental Economics. London : Macmillan Press, 1997. ISBN 0333582365.

KAHNEMAN, D. - KNETSCH, J. L. 1992. Valuing public goods: the purchase of moral satisfaction. In. Journal of Environmental Economics and Management, 1992, no. 22, p. $57-70$.

KAHNEMAN, D. 1986. Comments. In: Cummings, R. G. - Brookshire, D. S. - Schulze, W. D. (Eds), Valuing Environmental Goods: An Assessment of the Contingent Valuation Method. Rowman \& Allanheld, Totowa.

KALLAS, Z. - GÓMEZ-LIMÓN, A. - HULÉ, J. B. 2007. Decomposing the Value of Agricultural Multifunctionality: Combining Contingent Valuation and the Analytical Hierarchy Process. In: Journal of Agricultural Economics, vol. 58, 2008, no. 2, p. 218-241.

KRISTRÖMM, B. 1995. A Non-parametric Approach to the Estimation of Welfare Measures in Discrete Responses Valuation Studies. In: Land Economics, vol. 66, 1995, no. 2, p. 135-139.

KŘŮMALOVÁ, V. 2002. Evaluation of chosen benefits on environment and landscape coming from Czech agriculture. In: Agricultural Economics, vol. 48, 2002, no. 1, p. 13-17.

KUBÍČKOVÁ, S. 2004. Contingent Valuation of the Landscape Amenity Function of Agriculture in the White Carpathians Protected Landscape Area. Development of the Czech Society in the European Union: V. Lectures in Non-market Valuation Methods in the Environmental Area, Charles University in Prague, Matfyzpress, 2004, p. 259-268.

MARSDEN, T. - MURDOCH, J. 2006. Introduction between the Local and the Global: Confronting Complexity in the Contemporary Food Sector, in Terry Marsden, Jonathan Murdoch (ed.) Between the Local and the Global. Research in Rural Sociology and Development, Emerald Group Publishing Limited, vol. 12, 2006, pp.1-8.

MARSDEN, T. - SONNINO, R. 2005. Rural development and agri-food governance in Europe: tracing the development of alternatives. In: Higgins, V., Lawrence, G. (Eds.),
Agricultural Governance: Globalization and the New Politics of Regulation. London : Routledge, 2005.

MARSDEN, D. 2003. Adapting European labour institutions to global economic and technical change. In: Touffut, Jean-Phillipe, (ed.) Institutions, innovation and growth: selected economic papers. Edward Elgar/Saint-Gobain Centre for Economic Studies, Cheltenham, UK, pp. 45-67. ISBN 9781843765271.

MITCHELL, R. C. - CARSON, R. T. 1989. Using Surveys to Value Public Goods: The Contingent Valuation Method. Resources for the Future, Washington, DC.

OECD. 2003. Multifunctionality: The Policy Implications. Organisation for Economic Cooperation and Development. OECD Publications. Available at: http://www.oecd.org.

PLOEG, J. D. VAN DER - LONG, A. - BANKS, J. (eds). 2002. Living Countrysides. Rural development processes in Europe: the state of art, Elsevier B.I., Doetinchem.

PLOEG, J. D. van der, et al. 2000. Rural development: from practices and policies towards theory, in Sociologia Ruralis, vol. 40, 2000, no. 4, pp. 391-408.

SAATY, T. L. 1980. The Analytic Hierarchy Process. New York : McGraw-Hill, 1980.

SAATY, T. L. 1991. Response to Holder's comments on the analytic hierarchy process. In: The Journal of the Operational Research Society, 1991, no. 42, p. 909-914.

SAMPLES, K. - HOLLYER, P. 1990. Contingent valuation of wildlife resources in the presence of substitutes and complements. In: Johnson, R. L. - Johnson, G. V. (Eds.). In: Economic Valuation of Natural Resources. Westview Press, Boulder, C0, 1990, pp. 177-192.

SCHKADE, D. A. - PAYNE, J. W. 1993. Where do the numbers come from? how people respond to contingent valuation questions. In: Hausman, J. A. (Ed.). Contingent Valuation: A Critical Assessment. North Holland Press, Amsterdam, 1993, pp. 271-304

STEVENS, T. H. - ECHEVERRIA, J. - GLASS, R. J. - HAGER, T. - MOORE, T. A. 1991. Measuring the existence value of wildlife: what do CVM estimates really show? In: Land Economics, 1991, no. 67, p. 390-400.

\section{Contact address:}

Ing. Simona Miškolci, Ph.D., Department of regional and business economics, FRRMS MZLU in Brno, Zemědělská 1, 61300 Brno, phone: 54513 64 07, Czech Republic, e-mail: motyl@mendelu.cu 